\title{
A BAIXA PROCURA PELA LICENCIATURA EM FÍSICA, COM BASE EM DEPOIMENTOS DE ESTUDANTES DO ENSINO MÉDIO PÚBLICO DO OESTE CATARINENSE
}

\author{
The shortage of physic's teachers in Brazil: origins \\ of the decreasing search for a degree course in Physics \\ from the students' testimony of the public secondary \\ education in the Western inhabitant of Santa Catarina
}

\author{
Mércio José Lunkes ${ }^{1}$ \\ João Bernardes da Rocha Filho ${ }^{2}$
}

\begin{abstract}
Resumo: $\mathrm{O}$ artigo contextualiza a carência de professores de nível médio, especialmente de Física, e apresenta resultados de uma pesquisa com estudantes do Ensino Médio público do Oeste catarinense, sobre expectativas e críticas em relação à carreira do magistério em Física. Foram investigados, em 2007, 157 alunos de $1^{\mathrm{a}}$ série, e, em 2009, 132 alunos remanescentes, então na $3^{\text {a }}$ série. Da análise dos dados colhidos, identificou-se que os estudantes entram no Ensino Médio sem expectativas elevadas, mas com gosto pelo ensino de ciências, e saem dele com baixo interesse pela carreira docente em Física, impressionados pela ênfase da formulação matemática, a pouca aplicação cotidiana dos conteúdos estudados e a baixa valorização social do magistério. Foram identificados eventos escolares típicos, que ocorreram durante o Ensino Médio dos estudantes investigados, parcial ou totalmente responsáveis pela modificação de atitude dos estudantes, culminando na rejeição pela carreira do magistério em Física.
\end{abstract}

Palavras-chave: Magistério em Física. Ensino de Física. Carência de professores.

\begin{abstract}
The subject of this article is the high school level Physics teacher shortage, and research into students of public schools in Santa Catarina state, on the expectations and criticism of the professional choice of teaching in Physics. This research investigated, in 2007, 157 pupils of the 1st series, and, in 2009, 132 of the same pupils, then in the 3rd series. The analysis identified that students join secondary education without elevated expectations but appreciating Physics, and they conclude their courses with a low interest in teaching, negative impressions of the emphasis on mathematical formulation, poor daily life application of the contents studied and the low social value of the teaching. We identified a series of typical school events, which took place during the secondary education of the investigated students, which were responsible for the modification of attitude of the students, culminating on the rejection for a professional career in teaching in Physics.
\end{abstract}

Keywords: Teaching in Physics. Teaching of Physics. Shortage of teachers.

${ }^{1}$ Licenciatura em Física, mestrando em Educação em Ciências e Matemática. Professor de Física no Sistema Público de Ensino. Formosa do Sul, SC, Brasil. <merciojl@hotmail.com>

${ }^{2}$ Licenciatura em Física, doutor em Metrologia e Instrumentação. Docente e pesquisador, Programa de Pós-Graduação em Educação em Ciências e Matemática, Faculdade de Física, Pontifícia Universidade Católica do Rio Grande do Sul. Porto Alegre, RS, Brasil. <jbrfilho@pucrs.br>

${ }^{1}$ Av. Primo Alberto Bodanese, 1227

EEB Professora Jurema Savi Milanez - Quilombo, SC

$89.850-000$ 
Lunkes, M. J.; Rocha Filho, J. B.

\section{Introdução}

Dados do IBGE (INSTITUTO BRASILEIRO DE GEOGRAFIA E ESTATÍSTICA, 2009) relativos ao mês de abril de 2009 indicaram uma taxa de desocupação de 8,90\% da população economicamente ativa, significando que existem, no Brasil, cerca de dois milhões de desempregados em idade produtiva. Esse índice de desemprego se modifica dependendo do grau de instrução, da idade, da experiência e da formação técnica do trabalhador, porém atinge, em maior ou menor intensidade, quase a totalidade das profissões. $\mathrm{Na}$ carreira do magistério em Física, no entanto, esse índice aparece invertido, e há mais de 50 mil vagas para professores de Física, conforme relatório de 2007 emitido pela Câmara de Educação Básica, do Conselho Nacional de Educação, do Ministério da Educação e Cultura - MEC/CNE/ CEB (IBAÑEZ RUIZ; RAMOS; HINGEL, 2007). As vagas a descoberto estão distribuídas em todos os estados do País, com tendência de ampliação conforme mais e mais cidadãos são atendidos pelos sistemas de educação escolar. As salas de aula das escolas brasileiras, segundo Ibañez Ruiz, Ramos e Hingel (2007), em levantamento realizado e publicado pelo MEC, estão carentes de professores habilitados para a área de Física e, em grau menor, para Química, seguida por todas as demais disciplinas do Ensino Médio. A situação mais preocupante é a da Física, pois, segundo este levantamento, apenas $9 \%$ dos profissionais em exercício no magistério desta disciplina possui habilitação na área.

Esse problema contemporâneo e premente gerou a motivação para a investigação das possíveis causas para o desinteresse dos jovens em relação à carreira docente em Física, que são apresentadas neste artigo.

\section{Uma breve discussão sobre a formação de professores no Brasil e a rejeição pela carreira docente}

Partindo do pressuposto de que, como pensa Moraes (1998), a educação tem como objetivo a promoção da equidade (igualdade de oportunidades), ela deve permitir o acesso igualitário aos conhecimentos historicamente construídos, e que estes sejam significativos para o grupo social em formação, bem como para os demais indivíduos que participam da comunidade ampla que forma a sociedade. No entanto, segundo Gobara e Garcia (2007), a educação escolar no Brasil teve início em 1549, na Bahia, e durante o período colonial se caracterizou como uma oportunidade destinada a poucos. A partir da era Vargas, já no século $\mathrm{XX}$, houve um processo de consolidação do capitalismo por meio do desenvolvimento de indústrias diversas, bem como o surgimento de setores econômicos outrora inexistentes, dentre os quais se destacou o de serviços. Esse processo despertou a necessidade de diferentes tipos de qualificação para a mão de obra, pela ampliação da exigência de conhecimentos especializados, influenciando a forma como os trabalhadores encaravam a escolarização e o conhecimento formal. A escola passou a exercer, assim, a função de preparação desses trabalhadores para as exigências profissionais dos novos tempos, de modo a torná-los aptos para a aprendizagem posterior das técnicas que utilizariam no trabalho.

A crescente industrialização produziu acentuado êxodo rural e acúmulo populacional nas cidades nas quais havia maior possibilidade de trabalho, porém os trabalhadores rurais não 
possuíam qualificação para as novas tarefas industriais, não estando aptos a desempenharem as funções especializadas necessárias às empresas que dispunham de vagas. Esse fenômeno contribuiu para a expansão do ensino público, que assumiu o papel de formador de mão de obra básica e incentivou a criação de sistemas educacionais independentes, vinculados ao setor industrial e de serviços, responsáveis pelo oferecimento de cursos profissionalizantes. Assim, enquanto às escolas particulares restou, sobretudo, instruírem os filhos dos donos de capital, às escolas públicas foi destinado atenderem, preponderantemente, a população desfavorecida economicamente, constituída especialmente de filhos de proletários (SAEZ, 2008).

Esse caráter, porém, se manifestou opostamente nas universidades públicas, cujo processo de seleção exigente, associado ao baixo número de vagas, privilegiou os que haviam recebido Educação Básica em escolas particulares. Com base em Ataíde, Lima e Alves (2006), pode-se compreender que a educação escolar despertou como principal mecanismo de ascensão social, e a universidade se firmou como caminho quase único para os indivíduos que almejavam melhorar seu status social. Segundo os autores, a situação vivenciada, hoje, pelo Ensino Superior público brasileiro também ainda reflete as políticas características do período colonial, e desde o seu surgimento preserva certos mecanismos socialmente excludentes.

Embora as formas de admissão estejam se modificando sob a ação de políticas afirmativas muito recentes, a rigorosa seletividade do passado limitou o acesso, ao Ensino Superior público, dos segmentos menos favorecidos da população. Uma pesquisa realizada pela Associação Nacional dos Dirigentes das Instituições Federais de Ensino Superior (ASSOCIAÇÃO NACIONAL DOS DIRIGENTES..., 2004), por exemplo, mostrou que, na Região Sul do Brasil, 68,9\% dos estudantes das Instituições Federais de Ensino Superior (IFES) pertencem às classes A e B, e que apenas 21,1\% pertencem às classes $\mathrm{C}, \mathrm{D}$ e E. Os números das outras regiões do País, mostrados na mesma pesquisa, indicam situação semelhante, embora com números um pouco menos expressivos. Parece claro que há uma tendência das IFES a acolherem, preferencialmente, os mais abastados, sobretudo naqueles cursos mais procurados, para os quais os concorrentes que estudaram em escolas particulares e cursinhos pré-vestibulares são naturalmente aprovados com maior frequência.

Embora este quadro esteja gradualmente se modificando, especialmente como efeito de ações de políticas públicas na área da educação tomadas na última década, a universidade pública brasileira ainda é reduto das classes mais favorecidas, que estudaram nas melhores e mais caras escolas particulares, e que não almejam a carreira docente. Por isso, a ANDIFES calcula que mais de $70 \%$ dos professores que estão aptos a atuarem no mercado de trabalho são formados pelas instituições particulares de Ensino Superior (ASSOCIAÇÃO NACIONAL DOS DIRIGENTES..., 2008). Mas nestas instituições os alunos têm de custear diretamente sua formação, pagando mensalidades geralmente altas quando comparadas às suas rendas pessoais. Talvez justamente por isso esses estudantes sonhem com um futuro melhor escolhendo profissões cujos status sociais e possibilidades de ganhos compensem o esforço que fazem; e a licenciatura em Física raramente é a escolhida porque há, no imaginário popular, uma identificação entre o magistério e os baixos salários, além de um preconceito associado à dificuldade de se aprender esta ciência. Essa situação também afasta os alunos de uma opção profissional em favor das licenciaturas em geral. Nas IFES, a maioria dos estudantes, que pertence às classes $\mathrm{A}$ e $\mathrm{B}$, não deseja o magistério, pois vêm de famílias com tradição em profissões liberais ou proprietárias de empresas, e pretendem seguir nesses mesmos ramos. 
Lunkes, M. J.; Rocha Filho, J. B.

Nas universidades particulares, por sua vez, o sonho da ascensão social via graduação tem o mesmo efeito, e o resultado comum é que temos poucos professores em formação.

A baixa procura pelos cursos de licenciatura parece, portanto, se relacionar, sobretudo, com a questão do status social do magistério, que tem estreita relação com a questão salarial, mas não é totalmente coerente com ela. Embora os professores dos níveis iniciais das redes públicas estaduais recebam salários realmente baixos, se o professor seguir em formação continuada poderá ingressar em escolas particulares e até no magistério superior, com substancial aumento de renda. Isso é especialmente válido para a licenciatura em Física, devido à carência de professores dessa área, e sugere que a percepção quanto ao valor da profissão docente sofre influências decisivas de fatores menos objetivos do que a simples comparação das possibilidades salariais reais.

A situação das 134 licenciaturas presenciais em Física no Brasil (LEITE; PACHANE, 2008) é mais grave que a de qualquer outra licenciatura, com a oferta de vagas muito superior à procura; e o Instituto Nacional de Pesquisas Educacionais Anísio Teixeira (2003) mostra, por exemplo, que, de 1990 a 2001, foram licenciados, em Física, apenas 7.216 estudantes, contra uma demanda acumulada de 55.231 professores. Além disso, com a ampliação de atuação dos físicos na pesquisa, na indústria, na área pericial, de metrologia e, sobretudo, na área médica, somente uma parcela dos licenciados passou a atuar na docência (ARAÚJO; VIANNA, 2008a). O número anual de licenciandos que concluem seus estudos é insuficiente perante a demanda crescente pela Educação Básica, e conforme Rocha Filho, Basso e Borges (2007), as poucas vagas preenchidas nos cursos de licenciatura em Física sugerem que as escolas continuarão indefinidamente carentes desses profissionais.

Da análise do contexto socioeconômico e profissional dos professores, Penha (2005), Gobara e Garcia (2007) inferem que os cursos de licenciatura em Física apresentam vagas ociosas como decorrência do baixo status social dos licenciados em relação a outros profissionais, bem como dos salários pouco atrativos que professores das redes públicas comumente recebem. Araújo e Vianna (2008a) chamam a atenção para a diferença salarial em relação a outras profissões que exigem grau de instrução semelhante, e inclusive em relação àquelas que têm exigências formais menores. Sobre isso, o relatório do Instituto Nacional de Estudos e Pesquisas Educacionais Anísio Teixeira (2003) afirma que "um professor que atua em nível médio ganha, em média, quase a metade da remuneração de um policial civil” (p. 47). Considerando o status social que o salário oferece e os benefícios do plano de carreira, ser policial é vantajoso em relação ao magistério. Araújo e Vianna (2008a) apontam, ainda, que os problemas que envolvem a carência de professores de Física no Brasil extrapolam a questão salarial, pois envolvem também questões metodológicas, de infraestrutura e de políticas públicas condizentes com o significado da educação perante o desenvolvimento do País. Não se deve esquecer que, conforme Moraes (2004), o desenvolvimento de uma nação, nos setores econômico, tecnológico e intelectual, passa pela qualidade da educação oferecida à população. 
A baixa procura pela licenciatura em Física...

\section{Se há uma bem conhecida rejeição dos estudantes do nível médio pelas licenciaturas, por que investigar a rejeição especificamente pela Física?}

A definição pela pesquisa da rejeição pela licenciatura em Física em uma escola pública do Oeste de Santa Catarina está associada à região na qual um dos autores atua como professor de Física no Ensino Médio público, o que facilitou o acesso às escolas e professores. Além disso, a carência de professores de Física é maior nas regiões afastadas dos grandes centros urbanos, e maior do que a carência de professores de qualquer outra disciplina do nível médio. Os objetivos desta pesquisa foram escolhidos considerando-se que é preciso identificar diretamente os motivos que levam os estudantes da Educação Básica a optarem por não seguirem a carreira do magistério nesta ciência, pois somente assim será possível planejar ações destinadas a responder a esta demanda não atendida.

É notável que os jovens que chegam à universidade e que, portanto, tiveram contato frequente com a Física e com professores de Física, não sejam favoravelmente influenciados por este contato quanto à decisão pela carreira de nível superior. O que de fato ocorre é justamente o oposto. Este é um dado difícil de ser compreendido porque é razoável supor que alunos do Ensino Médio têm poucas informações objetivas sobre a maior parte das profissões de nível superior, exceto aquelas com as quais tiveram contato ao longo da infância e adolescência. Os jovens tendem a receber informações mais realistas relativamente às profissões de seus familiares, professores e outros profissionais com os quais se relacionaram mais frequentemente, em relação às profissões que conhecem apenas pelos meios de comunicação, que podem receber conotações romanceadas, com características presumidas mais distantes da realidade. No entanto, parece que justamente estas profissões pouco conhecidas são as que mais os atraem, e que escolhem em detrimento das que conhecem com mais detalhes.

A importância da pesquisa, assim, está associada aos números críticos para os quais o Ministério da Educação chama a atenção, que mostram que a licenciatura em Física forma até 13 vezes menos professores que outras licenciaturas (IBAÑEZ RUIZ; RAMOS; HINGEL, 2007). Uma única licenciatura formou menos professores que a Física entre 1990 e 2005, mas esse caso pode ser considerado justificado porque se trata de uma língua estrangeira pouco difundida no País, e ensinada em caráter facultativo nas escolas. A posição relativa da Física, mostrada neste documento (IBAÑEZ RUIZ; RAMOS; HINGEL, 2007), sugere que a situação socioeconômica dos professores em geral não deve ser a resposta única à questão da falta de docentes de Física, caso contrário a carência tenderia a ser uniforme entre as diferentes áreas. Parecem existir fatores de rejeição extras em relação à Física, quando comparada ao magistério de outras áreas e disciplinas, e por isso é estratégico conhecê-los.

\section{A pesquisa}

Para identificar os fatores de rejeição à carreira docente em Física foi realizada uma pesquisa de longa duração, que envolveu um mesmo grupo de alunos desde o início até o final do Ensino Médio. Estes alunos foram questionados por meio de um instrumento escrito aplicado, inicialmente, a 157 alunos da primeira série do Ensino Médio, no segundo bimestre 
Lunkes, M. J.; Rocha Filho, J. B.

letivo do ano de 2007; e esse questionário focalizou, mais detidamente, as expectativas dos alunos acerca das aulas de Física, do curso em que estavam ingressando, e do futuro profissional que anteviam. Posteriormente, em abril de 2009, o mesmo grupo de alunos, então reduzido a 132 jovens cursando a terceira série, foi novamente questionado. Essa última coleta de dados utilizou um novo conjunto de perguntas, mais focado na busca por intenções de ingresso na carreira docente e nos motivos pelos quais esta despertaria, ou não, o interesse dos jovens.

\section{Questões do questionário aplicado em 2007:}

1) Como vê seu futuro profissional? Pensa em ser professor(a)?

escola?

2) Que diferenças você percebe entre a Física e as outras disciplinas ensinadas na

3) Você já pensou em fazer faculdade de Física? Por quê?

4) Quais suas expectativas em relação à Física que estudará no Ensino Médio?

\section{Questões do questionário aplicado em 2009:}

1) Como você percebe a valorização dos professores, em geral?

2) Considera a possibilidade de cursar Física para ser pesquisador? Por quê?

3) Considera a possibilidade de cursar Física para ser professor? Por quê?

As perguntas dos questionários tiveram um caráter amplo e aberto, inspiradas em Demo (2005), quando afirma, em relação à produção textual, que "elaborações próprias são infinitamente mais sensíveis" (p. 96), sobretudo por se tratar de pesquisa qualitativa naturalística, a qual, segundo Moraes (2006), pode ser compreendida como visando explicitar teorias implícitas que os sujeitos construíram anteriormente, de forma inconsciente. Essa tipologia de pesquisa permitiu colher informações fidedignas e relevantes, provenientes de um grande grupo de adolescentes, em uma época da vida em que suas motivações são mais fortemente permeadas por colorações emocionais.

As respostas obtidas foram submetidas à Análise Textual Discursiva que, segundo Moraes e Galiazzi (2007), consiste na desconstrução de textos objetivando a formação de categorias. Estas conduzem o pesquisador à elaboração de um novo texto, baseado nas ideias oriundas dos originais. Determinadas as categorias, as respostas foram associadas em grupos assemelhados, e a categorização foi representada graficamente, possibilitando a visualização imediata do coletivo dos dados colhidos durante o processo investigativo. Paralelamente a isso, a revisão bibliográfica embasou a análise, oferecendo suporte às categorias levantadas frente à análise dos resultados das respostas aos questionários.

\section{Resultados da análise}

\section{Dados de 2007}

Os dados colhidos com as turmas de primeira série, no ano de 2007, forneceram, sobretudo, informações relativas à disposição dos estudantes em relação ao magistério. Quando questionados acerca do futuro profissional, conforme o Gráfico 1, os estudantes demonstraram preferência pelas profissões liberais, com depoimentos tais como: "Nunca pensei em 
A baixa procura pela licenciatura em Física...

cursar licenciatura, pretendo cursar outra coisa, e não ser professora". Na etapa da vida em que os estudantes se encontravam ao serem questionados, uma resposta majoritária desta magnitude provavelmente estava mais relacionada com o status social presumido dos professores no imaginário dos estudantes do que com algum conhecimento ou tendência vocacional específica. Ocorre que, nesta idade, muitos jovens ainda têm pouca informação ou preocupação sobre a carreira profissional, mas pensam muito em termos de valorização social (ROCHA FILHO; BASSO; BORGES, 2007).

Outro aspecto, agora apresentado no gráfico 2, é a comparação entre a disciplina de Física com as outras disciplinas, e tornou-se evidente a ligação Física-Matemática. Isso transparece em quase todas as respostas, como nas seguintes frases: "Física é uma matéria parecida com a Matemática". - "Na verdade eu não entendo quase nada, talvez devido a sua relação com a Matemática". Aqui é possível fazer diferentes inferências, dependendo da conotação dada, pelos alunos, às disciplinas, porém fica explícito que eles não as diferenciam claramente. Como há distinções notáveis entre os conteúdos de uma e outra disciplina, e os estudantes parecem não perceber isso, é possível que os professores estejam utilizando metodologias impróprias para os objetivos educacionais da Física do Ensino Médio. É conhecido, também, que a educação em Física falha ao utilizar pouco ou inadequadamente a experimentação, a história da ciência e as aplicações práticas cotidianas da Física (LIMA et al., 2009), o que pode conduzir à matematização excessiva e à confusão que se manifesta nas respostas dos estudantes.

No questionamento acerca da possibilidade de futuramente cursar Física, mostrado no Gráfico 3, os educandos, em maioria, alegaram nunca terem considerado essa opção. Eles preferem Medicina, Direito e Administração, entre outras faculdades que conduzem a funções que, atualmente, têm maior valorização social. - "Nunca pensei em fažer faculdade Física, pois penso

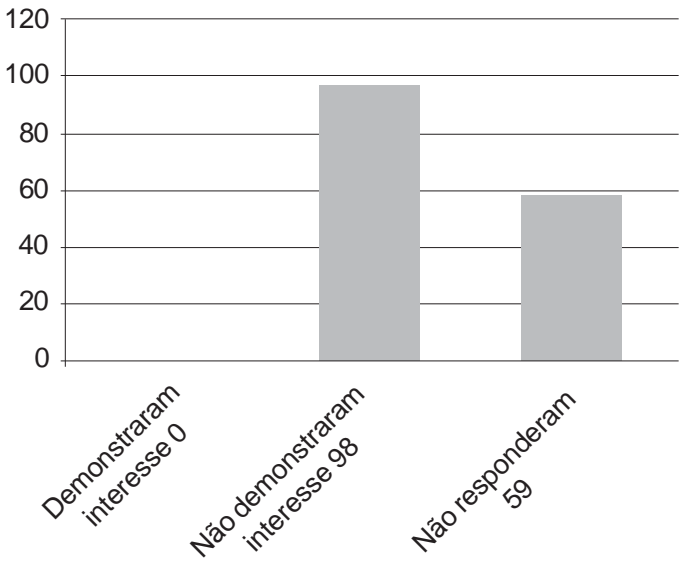

Gráfico 1. Interesse dos estudantes na carreira docente, segundo as respostas ao questionário de 2007.
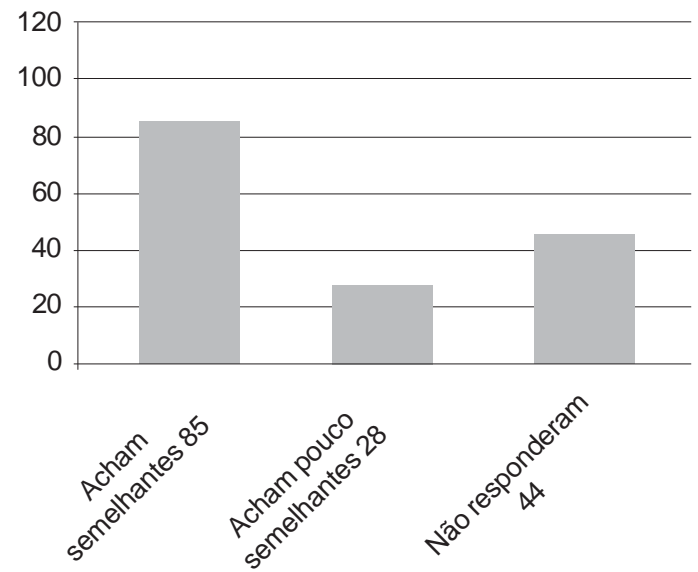

Gráfico 2. Semelhança da Física com a Matemática ensinada na escola, na opinião dos estudantes questionados em 2007. 
em fazer uma faculdade de Medicina". - "Estou interessada em cursar faculdade de Administraşão". Surge a desvalorização social cruzada do magistério e da Física. As respostas denotam uma rejeição cuja origem parece ser anterior ao momento atual dos estudantes investigados, pois eles dizem que sequer aventaram a hipótese de serem professores. Como nessa altura da vida os jovens têm, em geral, poucas informações objetivas sobre muitas carreiras profissionais, exceto aquelas exercidas pelas pessoas com quem convivem muito proximamente, a rejeição provavelmente se fundamenta nos dados esparsos trazidos pelos meios de comunicação, e carece de bases factuais. Assim, os sistemas educacionais, em geral, especialmente no nível do Ensino Médio, deveriam oportunizar, aos estudantes, acesso a dados realistas das muitas profissões existentes, já que, em breve, estes adolescentes irão escolher uma carreira.

$\mathrm{Na}$ questão relacionada à expectativa em relação às aulas de Física, com resultados mostrados no Gráfico 4, os estudantes declararam esperar "poucas provas" e outras facilidades, para "terminar logo" o Ensino Médio e conseguir emprego remunerado. - "Espero que en ganhe boas notas para passar de ano". - "Eu espero ganhar boas notas, e quando sair daqui, arranjar um emprego". Cerca de um quarto dos estudantes declarou que via, nos conhecimentos físicos, uma oportunidade de compreender ou atuar sobre a realidade extraescolar, com respostas do tipo: - "Eu espero estudar Física para facilitar meu dia-a-dia, lá fora, no meu trabalho". Esta proporção relativamente elevada indicou que havia uma boa predisposição para a aprendizagem científi$\mathrm{ca}$, e que estes alunos estavam receptivos às propostas que lhes fossem apresentadas no ciclo que se iniciava. Essa é uma constatação importante, pois, dois anos mais tarde, essa receptividade se transformou em desapontamento, como mostra a análise tardia.

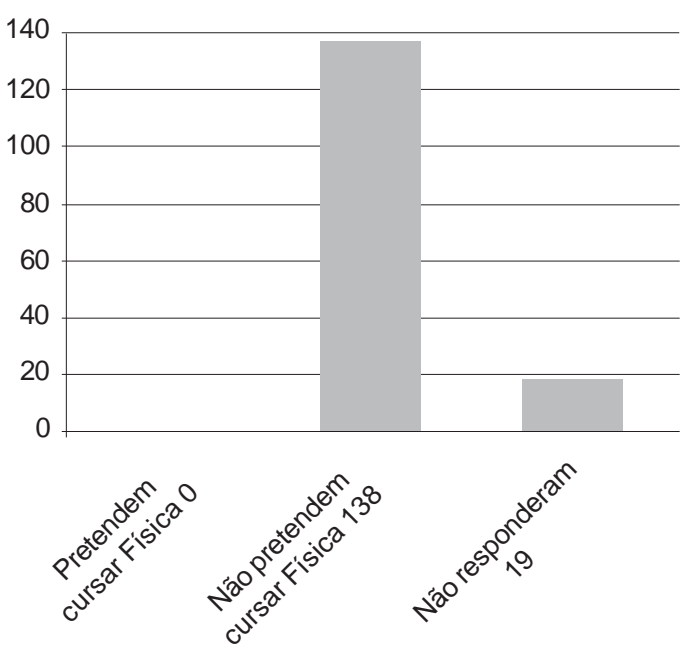

Gráfico 3. Intenção dos estudantes em cursarem Física no Ensino Superior, nos depoimentos de 2007.

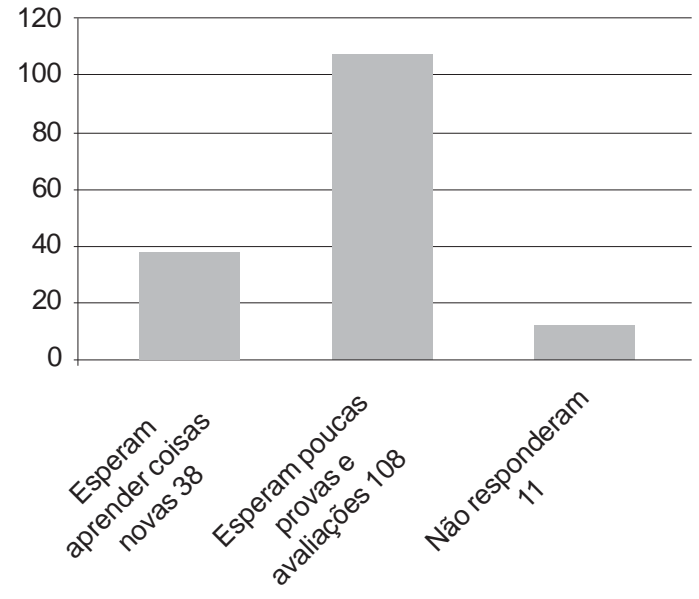

Gráfico 4. Expectativas dos estudantes em relação à Física ensinada no Ensino Médio, nos depoimentos de 2007. 
A baixa procura pela licenciatura em Física...

Um depoimento que chama a atenção foi o de um aluno que disse gostar da disciplina Ciências do Ensino Fundamental, mas que, no Ensino Médio, com a divisão das Ciências em disciplinas separadas de Química, Física e Biologia, mudou de opinião. Essas novas disciplinas independentes parecem ter baixo nível de significação para os alunos por estarem fracamente relacionadas entre si e com o cotidiano, mostrando grau elevado de dificuldade aos alunos, exigindo níveis de abstração que eliminam a possibilidade de conexão com a realidade cotidiana individual. Essa divisão provoca uma espécie de choque, que gera aversão às disciplinas científicas. Essa é uma constatação contraditória em relação ao que se espera do Ensino Médio, segundo os documentos oficiais que orientam este nível de escolarização, que contemplam mais a preparação de um cidadão capaz de refletir sobre ciência e tecnologia do que a formação de um cientista mirim.

\section{Dados de 2009}

Os dados colhidos no ano de 2009, com os mesmos estudantes questionados em 2007, frequentando, então, a terceira série do Ensino Médio, trouxeram a complementação necessária para o equacionamento da questão em termos dos objetivos propostos na pesquisa.

Quando questionados acerca da profissão docente, a opinião mais frequentemente emitida foi a de que o professor é pouco valorizado, como mostrado no Gráfico 5. - "Não é valorizada ao ponto que deveria ser. Hoje, os professores, pode se dizer que são explorados, seus salários não são dignos de seu tamanho esforço". - "É uma profissão pouco valorizada e respeitada". - "Seria uma profissão boa se o professor fosse valorizado pelo seu serviço e seus direitos". Esse aspecto parece não se modificar em relação às respostas dadas ao questionário anterior, significando que a atuação dos professores do Ensino Médio não afetou a impressão negativa sobre a carreira do magistério em geral, que os alunos já tinham ao ingressar neste ciclo. Este é um fenômeno interessante e passível de ser investigado posteriormente.

Em relação ao questionamento acerca da possibilidade de cursarem Física para serem pesquisadores, alguns estudantes responderam que cursariam, mas não para atuarem como professores. - "Eu cursaria Física, mas não para trabalhar na escola como professora"; mas a maioria respondeu que não se acha capaz de estudar Física na universidade, ou que tem outros planos para o futuro profissional. O gráfico 6 sintetiza as informações colhidas, que sugerem que os estudantes reconhecem a importância da Física, como ciência, mas não veem a carreira como uma possibilidade profissional real.

$\mathrm{Na}$ questão acerca da opção profissional pela licenciatura em Física, a maioria dos estudantes manifestou desinteresse devido, novamente, à baixa valorização profissional e status social dos professores. As respostas foram sintetizadas no Gráfico 7. Algumas respostas típicas foram: - "Não cursaria faculdade nenhuma de licenciatura, pois tenho outro objetivo para minha vida". - "Não cursaria Licenciatura de Ciências on Matemática, por que são matérias muito complicadas e en já tenho outra profissão prevista para o futuro". - "Não cursaria Licenciatura, porque o salário é muito baixo, para a quantidade que precisa estudar". Apenas duas alunas se mostraram interessadas em cursar licenciatura em Física: - "Eu pretendo cursar Licenciatura em Física, pois ela mexe com bastante experimentos, ela envolve o cotidiano em si". - "Sim, porque a Física estuda um assunto que interessa a todos, e eu pretendo cursar essa matéria, porque en gosto de assuntos como eletricidade e movimentos". 


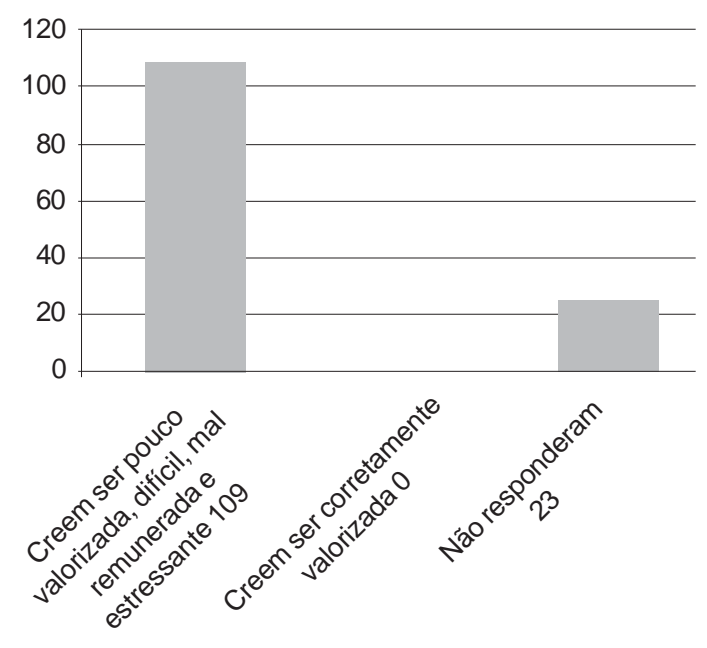

Gráfico 5. Percepção dos estudantes quanto às características valorativas da profissão docente, em 2009.

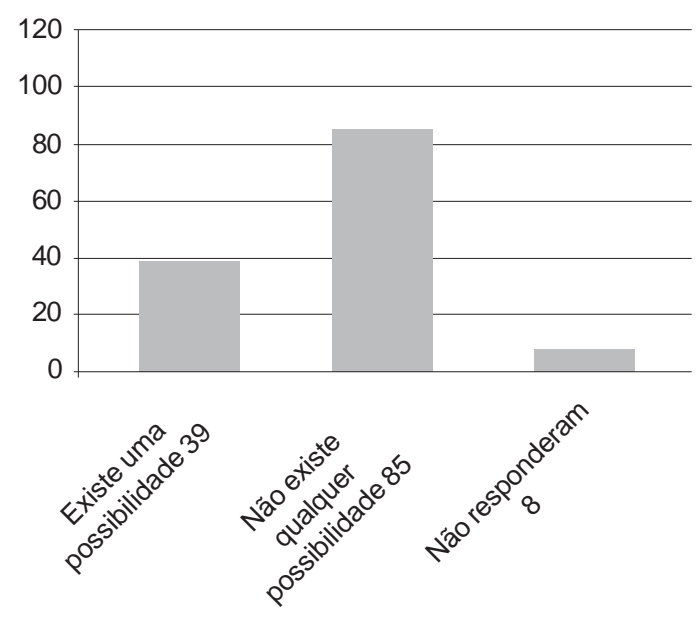

Gráfico 6. Possibilidade hipotética de cursar Física, nas respostas de 2009.

Embora a pergunta tenha envolvido explicitamente a licenciatura em Física, a quase totalidade dos estudantes manifestou repúdio generalizado a qualquer licenciatura. Curiosamente, dados informais colhidos posteriormente à finalização da pesquisa indicam que há mais ex-alunos participantes desta investigação que hoje estudam em cursos superiores de licenciatura do que indicou o número quase nulo de estudantes que planejavam fazê-lo. Isso sugere que pode ocorrer uma pequena reversão no interesse profissional, em favor das licenciaturas, mais no final do último ano do Ensino Médio, ou logo depois que este é concluído.

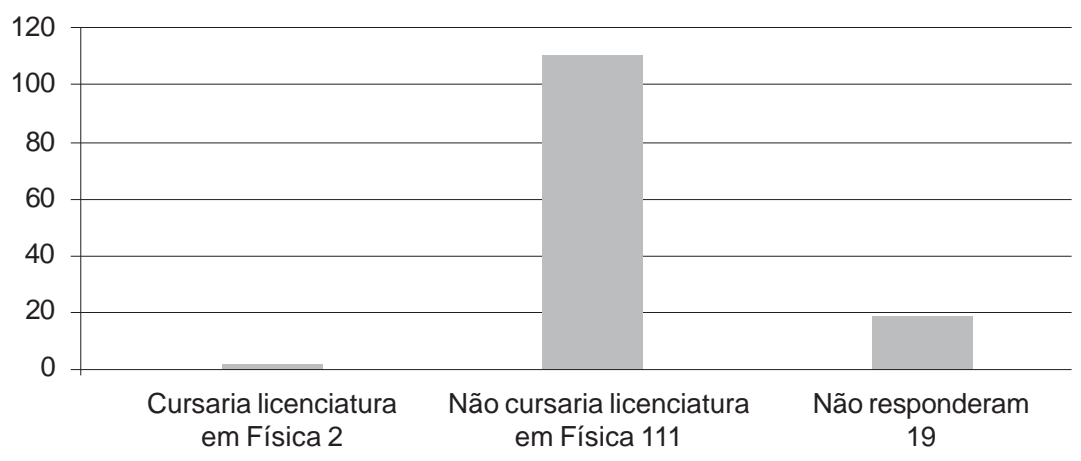

Gráfico 7. Possibilidade dos estudantes cursarem licenciatura em Física, nas respostas de 2009. 
Da análise das respostas é possível abstrair que a maioria dos estudantes demonstra preferência por profissões diferentes das docentes, de modo semelhante ao que surgiu no questionário anterior. Isso novamente deve estar relacionado à desvalorização do trabalho do professor, à baixa remuneração e à dificuldade das matérias envolvidas, pois as respostas mostraram que os estudantes valorizam adequadamente a Ciência, embora rejeitem maciçamente a profissão docente. Apenas duas alunas se mostraram interessadas em cursar licenciatura em Física, e alegaram que isso se relaciona aos temas e à forma como os conteúdos foram abordados durante os anos de Ensino Médio. Essas alunas relataram acreditar no futuro da profissão docente, pois “- a educação é o caminho que conduz ao desenvolvimento". - "Então, não adianta todo mundo almejar outras profissões, se diminuir a quantidade de professores babilitados, essa, causará uma perda na qualidade dos futuros profissionais das diversas áreas".

Chama a atenção o fato de essas estudantes se referirem à necessidade da existência de profissionais de todas as áreas, demonstrando uma consciência social elevada. Elas perceberam que, assim como precisamos de médicos, de advogados, de administradores e de cientistas, precisamos, também, de professores capazes de formarem todos os outros.

\section{Conclusões}

Os resultados da investigação sugerem que, para o grupo de estudantes investigado, a rejeição à carreira do magistério em Física está associada de forma importante à rejeição pela carreira docente em geral, que se origina já no decorrer do Ensino Fundamental e que se fortalece ao longo do Ensino Médio. As origens dessa rejeição parecem envolver, sobretudo, no início do Ensino Médio, o status social dos professores, pois, nessa época da vida, os estudantes geralmente têm poucas informações objetivas acerca das profissões; mas, ao final deste ciclo de estudos, os motivos da rejeição parecem envolver, também, o pequeno significado que a Física escolar tem no cotidiano dos estudantes, e a complexidade matemática com que são abordados seus conteúdos neste nível, que produz neles a impressão de que não teriam capacidade para realizar estudos universitários nessa área. No início do Ensino Médio, os estudantes parecem ter uma atitude positiva em relação às Ciências, embora já manifestem desinteresse pela carreira do magistério, e, ao final desta etapa da escolarização, o desinteresse se amplia, provavelmente também pelo fracasso generalizado no aprendizado de Física.

Embora tenha sido explicitada por apenas um estudante, a manifestação sobre a ausência de continuidade entre a disciplina de Ciências, do Ensino Fundamental, e as disciplinas de Física, Biologia e Química, do Ensino Médio, assim como de inter-relação entre elas, merece consideração porque se originou de uma impressão íntima, não diretamente induzida pela questão que lhe foi colocada. Isso sugere que se trata de um ponto importante para o estudante, e pode indicar que, se uma ou mais perguntas fossem apresentadas sobre este tema aos ingressantes do Ensino Médio, mais estudantes se manifestariam de maneira similar.

A falta de significado que acompanha o ensino independente destas ciências é conhecida como uma decorrência nefasta da própria disciplinaridade, que os professores têm dificuldade em superar em face: das inúmeras exigências profissionais típicas do magistério, da decorrente falta de tempo, de deficiências na formação profissional e da disseminação de uma cultura competitiva em detrimento da cooperativa. No depoimento citado, o estudante tam- 
Lunkes, M. J.; Rocha Filho, J. B.

bém escreveu que, para ele, a Química se resume a fórmulas compostas por "letras, números e riscos" que não sabe "onde nem como aplicar", que a "Física mais parece a Matemática", e que a Biologia o "obriga a decorar nomes" que ele esquece, com "alegria, instantes após as provas".

Dada à familiarização dos jovens com a escola, podemos presumir que a carreira do magistério é uma das que eles conhecem melhor a esta altura da vida, porém as muitas horas despendidas em situações de encontro com professores parecem ampliar a rejeição em relação à carreira. Esse pode ser um dos fatores que levam os jovens a manifestarem maciçamente o interesse de seguir outras profissões, sobre as quais pouco ou nada sabem, rejeitando o magistério. A ampliação da má impressão quanto ao magistério ao longo do Ensino Médio, no nível imaginário dos estudantes pesquisados, indica que a mensagem que lhes foi comunicada nesse período foi negativa ou, pelo menos, não surtiu efeito positivo. Sabendo disso, uma modificação na atitude dos professores de Física, no sentido de esclarecer os alunos quanto às possibilidades da profissão, talvez possa ajudar a minimizar os efeitos dos preconceitos contra o magistério que se manifestam neste período.

Além disso, os resultados sugerem que os poucos interessados em seguir estudos na licenciatura em Física foram positivamente influenciados pela experimentação didática realizada no contexto escolar, e pelas aplicações dos conhecimentos físicos no cotidiano em que estavam inseridos. Isso conduz à suposição de que os recursos da contextualização e da experimentação, como argumentos educativos, não vêm sendo explorados adequadamente. Novamente, os impedimentos podem ser de mesma natureza que os salientados anteriormente, associados à falta de tempo para planejamento e deficiências de formação. Porém, se as tarefas de experimentar e contextualizar forem supostas essenciais para o bom desempenho pedagógico, os dirigentes das escolas e dos sistemas escolares se sentirão motivados a organizarem os horários de seus professores de modo a estabelecerem períodos de planejamento adequados. Mas essa conscientização passa, inicialmente, pelo professor, para somente, depois, transformar-se em política escolar ou política pública. 
A baixa procura pela licenciatura em Física...

\section{Referências}

ARAÚJO, R. S.; VIANNA, D. M. Baixos salários e a carência de professores de física no Brasil. In: ENCONTRO DE PESQUISA EM ENSINO DE FÍSICA, 11., 2008, Curitiba. Anais... Curitiba, 2008a. Disponível em: <http://www.sbf1.sbfisica.org.br/eventos/epef/ xi/sys/resumos/T0219-1.pdf>. Acesso em: 25 jul. 2009.

Discussões sobre a remuneração dos professores de física na educação básica.

Ciência em Tela, Campinas, v. 1, n. 2, p. 1-9, 2008b. Disponível em: <http:/ / www.cienciaemtela.nutes.ufrj.br/artigos/0208araujo.pdf>. Acesso em: 25 jul. 2009.

ASSOCIAÇÃO NACIONAL DOS DIRIGENTES DAS INSTITUIÇÕES FEDERAIS DE ENSINO SUPERIOR. Rede particular forma mais docentes. 2008. Disponível em: $<$ http:/ / www.andifes.org.br/index.php?Itemid=104\&id=137\&option=com_content\&task =view $>$. Acesso em: 14 ago. 2009.

Pesquisa do perfil socioeconômico e cultural dos estudantes de graduação das IFES. 2004. Disponível em: <http://www.andifes.org.br/index.php?option=com docman\&task $=$ doc_download\&gid=213\&Itemid=27>. Acesso em: 21 jul. 2009.

ATAÍDE, J. S. P.; LIMA, L. M.; ALVES, E. O. A repetência e o abandono escolar no curso de licenciatura em física: um estudo de caso. Physicae, Campinas, v. 6, n. 6, p. 21-32, 2006. Disponível em: <http://www.ifi.unicamp.br/physicae/ojs-2.1.1/index.php/physicae/ article/viewFile/101/82>. Acesso em: 13 jun. 2009.

DEMO, P. Educar pela pesquisa. Campinas: Autores Associados, 2005.

GOBARA, S. T.; GARCIA, J. R. B. As licenciaturas em física das universidades brasileiras: um diagnóstico da formação inicial de professores de Física. Revista Brasileira de Ensino de Física, São Paulo. v. 29, n. 4, p. 519-525, 2007. Disponível em: <http://www.scielo.br/ scielo.php?pid=S0102-47442007000400009\&script=sci_arttext>. Acesso em: 25 jul. 2009.

IBAÑEZ RUIZ, A. I.; RAMOS, M. N.; HINGEL, M. Escassez de professores no Ensino Médio: soluções emergenciais e estruturais. Brasília: Câmara de Educação Básica, 2007. Disponível em: <http://portal.mec.gov.br/cne/arquivos/pdf/escassez1.pdf >. Acesso em: 8 mar. 2010.

INSTITUTO BRASILEIRO DE GEOGRAFIA E ESTATÍSTICA. Pesquisa mensal de emprego: abril, 2009. Disponível em: <http://www.ibge.gov.br/home/estatistica/ indicadores/trabalhoerendimento/pme_nova/default.sht>. Acesso em: 31 maio 2009.

INSTITUTO NACIONAL DE ESTUDOS E PESQUISAS EDUCACIONAIS ANÍSIO TEIXEIRA. Estatísticas dos professores no Brasil. Brasília: INEP, 2003. Disponível em: $<$ http://www.inep.gov.br/download/censo/2003/estatisticas_professores.pdf>. Acesso em: 13 maio 2009. 
Lunkes, M. J.; Rocha Filho, J. B.

LEITE, S. A. G. O.; PACHANE, G. G. Licenciaturas no Brasil: estado-da-arte e evolução estatística por cursos entre 1997 e 2007. In: ENCONTRO DE INICIAÇÃO CIENTÍFICA DA PUC CAMPINAS, 8., 2008, Campinas. Anais... Campinas, 2008. Disponível em: $<$ http://www.puc-campinas.edu.br/pesquisa/ic/pic2008/resumos/Resumo/ \%7BC8636348-8501-4009-91CE-7D396EB90310\%7D.pdf>. Acesso em: 25 jul. 2009.

LIMA, V. M. R.; HARRES, J. B. S.; BORGES, R. M. R.; FILHO. J. B. R. Apresentação e avaliação de material de sustentação e experimentação em ensino de Física. Experiências em Ensino de Ciências, Porto Alegre, v. 4, n. 1, p. 7-22, 2009. Disponível em: <http:// www.if.ufrgs.br/eenci/artigos/Artigo_ID69/v4_n1_a2009.pdf>. Acesso em: 13 ago. 2009.

MORAES, M. C. Novas tendências para o uso das tecnologias da informação na educação. Brasília, 1998. Disponível em: <http://www.edutec.net/Textos/Alia/MISC/ edmcand2.htm>. Acesso em: 12 maio 2008.

O paradigma educacional emergente. Campinas: Papirus, 2004.

MORAES, R. Da noite ao dia: tomada de consciência de pressupostos assumidos dentro das pesquisas sociais. Porto Alegre, 2006. (Texto inédito).

MORAES, R.; GALIAZZI, M. C. Análise textual discursiva. Ijuí: Unijuí, 2007.

PENHA, S. P. A carência de professores de ensino de física : um estudo de caso sobre esta carência na região serrana do estado do Rio de Janeiro. In: SIMPÓSIO NACIONAL DE ENSINO DE FÍSICA, 16., 2005, Rio de Janeiro. Anais... São Paulo: Ciência à mão, 2005. Disponível em: <http://www.sbf1.sbfisica.org.br/eventos/snef/xvi/cd/resumos/T04152.pdf $>$. Acesso em: 28 maio 2009.

ROCHA FILHO, J. B.; BASSO, N. R. S.; BORGES, R. M. R. Transdisciplinaridade: a natureza íntima da educação científica. 2. ed. Porto Alegre: EDIPUCRS, 2007.

SAEZ, D. A. M. Escola pública e classes sociais no Brasil atual. Linhas Críticas, Brasília, v. 14, n. 27, p. 165-176, 2008.

Artigo recebido em janeiro de 2011 e aceito em fevereiro de 2011. 